Brit. J. vener. Dis. (1965), 41, 137.

\title{
AN OUT-PATIENT METHOD OF MARSUPIALIZATION FOR RECURRENT BARTHOLIN'S ABSCESSES*
}

\author{
BY \\ DAVID C. HUTFIELD \\ Department of Kenereal Diseases, St. Mary's Hospital, London
}

Marsupialization is a simple method of treatment for Bartholin's cysts and abscesses which aims at restoration of glandular function and prevention of recurrence. Davies (1948) was the first to use a method of treatment which aimed at restoration of glandular function. In 25 cases of Bartholin's cysts an incision was made close to the hymen in the region of the duct and a permanent sinus preserved by packing the cavity with iodoform gauze twice daily for 3 or 4 weeks. This method was not always successful because stenosis often occurred as a result of retraction of the cyst wall following resolution. Jacobson (1950) was the first to describe the operation of marsupialization in which he constructed a new mucocutaneous junction by suturing the cyst lining to the skin. In this operation part of the area of cyst wall was exposed by dissecting skin flaps before opening the cyst, a procedure which is no longer thought to be necessary. Nineteen cases were reported with good results. Wilder (1955) then reported a series of 32 cysts and 48 abscesses successfully treated by marsupialization. Following this, Tancer, Rosenberg, and Fernandez (1956) reported eleven cases of Bartholin's cysts successfully treated, and Blakey (1958) reported eight cases of cysts and six of abscesses all successfully treated by this method. Jacobson (1960) reported a second series of 140 patients who had had 152 cysts marsupialized with only four recurrences. Siganos (1961) described successful use of this treatment in ten cases of cysts and two of abscesses. Johnson (1961) then performed the operation successfully under pudendal nerve block and found it particularly useful in cases in which both sides were involved.

\footnotetext{
* Received for publication July 31, 1964
}

\section{Anatomy and Physiology}

Bartholin's gland, a homologue of Cowper's gland, is a very small racemose structure situated between and contained by the superficial and deep layers of the urogenital diaphragm. Oval-shaped and lobulated, it is connected to the introitus by a duct $2 \mathrm{~cm}$. long with its opening at the level of the posterior end of the labia minora, below the hymen. Histologically it is made up of numerous acini lined by a single layer of low columnar or cuboidal cells and a duct lined by transitional epithelium. Lying on the deep transverse perineal muscle and bulb, it is confined by dense fibrous tissue which prevents it from enlarging or becoming cystic when the point of obstruction is in the proximal portion of the duct. Instead, the damming up of secretions causes pressure atrophy and loss of function, associated with clinical symptoms of dryness of the vulva. Obliteration of the duct at its distal end causes cyst formation, since the gland continues to secrete its lubricating fluid.

The function of Bartholin's gland is to keep the vulva moist by secreting a small amount of thin, cloudy, viscid, and adherent fluid. It is stimulated by sexual excitement and the contents are discharged with the aid of the contracting muscles of the perineum.

\section{Pathology}

Inflammation of Bartholin's gland and its duct results in an attack of acute bartholinitis which may progress to abscess formation or in the absence of complete resolution may persist in chronic form, with recurrent exacerbations, leading to fibrosis. Partial or complete closure of the ostium occurs and in the presence of continued secretion a retention cyst 
lined by transitional epithelium is formed (Novak and Novak, 1958). Bartholin's cyst, therefore, is usually a cyst of the duct and not of the gland (Fig. 1). The contents are either a cloudy mucus or a yellowish-green purulent material which may be darkened by haemorrhage, but is usually sterile. Secondary infection as a result of a purulent vaginal discharge often leads to abscess formation. This can be caused by any pyogenic organism, but cultures usually produce a growth of Micrococcus catarrhalis, Streptococcus pyogenes, haemolytic or anaerobic streptococcus, or rarely of the gonococcus, for this organism has a predilection for columnar epithelium.

In excised Bartholin's cysts, evidence of infection is rarely shown in the racemose glandular elements, but is confined to the cyst wall and adjacent tissues.

\section{Technique of Marsupialization}

Reconstruction of the vulval mucocutaneous junction without interfering with the deeper portions of the gland, to effect adequate drainage, is the purpose of this operation. A vertical incision $3 \mathrm{~cm}$. long is made into the vaginal aspect of the cyst or abscess close to the ostium and lateral to the hymenal ring. The contents are drained and retraction prevented by grasping the lining with tissue forceps; drainage is completed by breaking down any loculi which may have retained fluid. Residual pus and necrotic debris are removed by irrigating with normal saline. The labial epithelium is then joined with the lining of the cavity by means of 6-10 interrupted No. 0 chromic catgut sutures. No further drainage or packing is required and the only necessary after-care comprises simple hygiene and daily baths.

\section{Case Reports}

Three cases of recurrent Bartholin's abscess, of which one was associated with acute gonococcal infection, were treated by marsupialization, one under general anaesthesia and the others under local infiltration analgesia.

Case 1, a 24-year-old woman, was admitted to the Nottingham Hospital for Women on September 7 . 1960 , with a history of 4 days' painful swelling on the left side of the vulva. This was associated with frequency of micturition but there had been no discharge. A leftsided Bartholin's abscess had been incised in 1959. The periods were regular and the last one had started on August 15, 1960. She had had no pregnancies.

Examination.-She was moderately ill, with a temperature of $99 \cdot 4^{\circ} \mathrm{F}$. and a pulse rate of $85 / \mathrm{min}$. The blood pressure was $120 / 80$ and a soft systolic murmur was audible over the apex of the heart. The thyroid gland was diffusely enlarged, but there were no signs of thyrotoxicosis. There was no other abnormality on general physical examination.

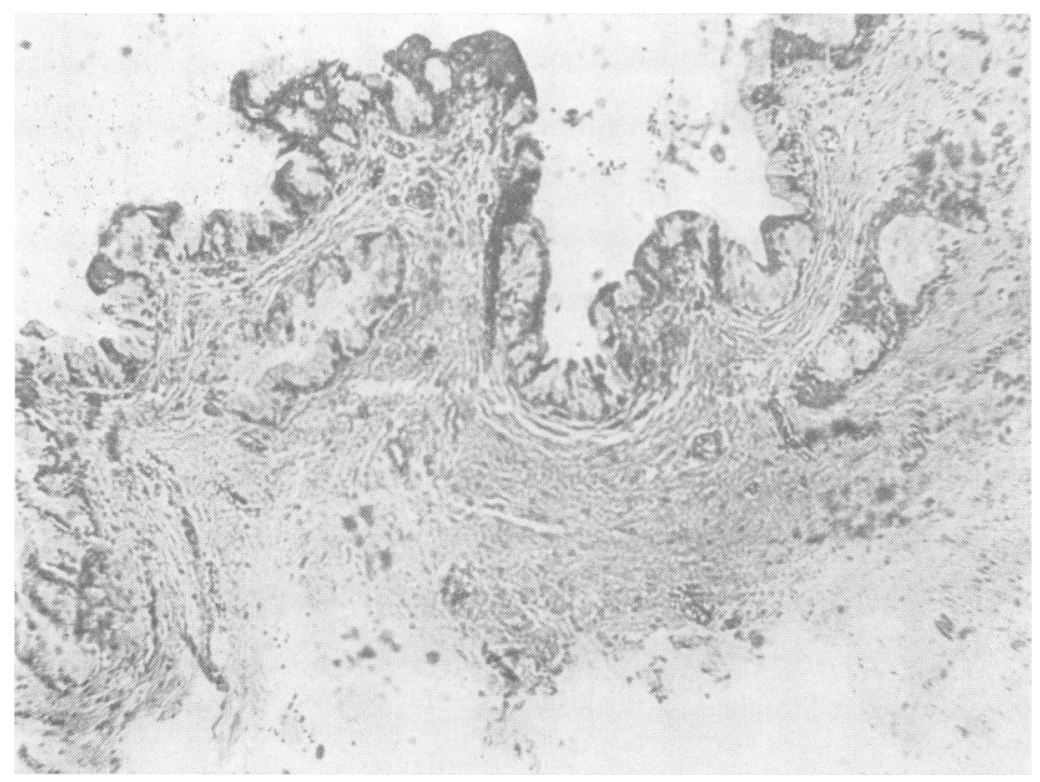

FIG. 1.-Microscopical section of Bartholin's cyst, showing lining of transitional epithelium. 


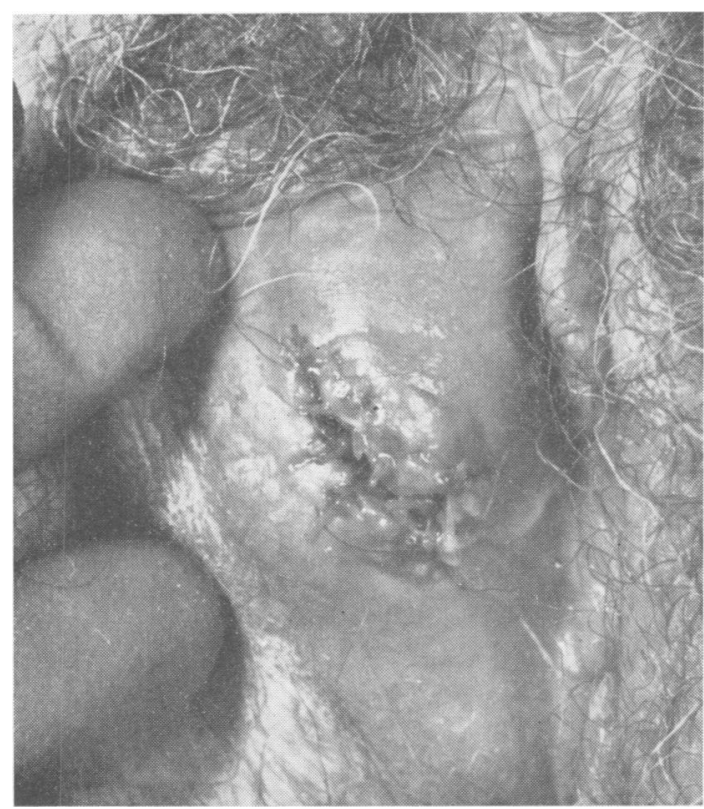

FIG. 2.-Sutures in situ 3 days after operation.

On the vulva there was a large tender red swelling 5 $\mathrm{cm}$. in diameter arising in the left labium majus beneath the line of origin of the labium minus. More extensive vaginal examination was not done at this stage.

Blood.-Hb $13.6 \mathrm{~g}$. per cent. (Haldane), white cell count 13,000 c. $\mathrm{mm}$. (10,050 neutrophils, 2,450 lymphocytes, 370 monocytes).

Operation.-She was prepared for the operating theatre and given Omnopon gr. 1/3 and scopolamine gr. 1/150 one hour beforehand. Following preliminary catheterization, incision and marsupialization were performed with the patient in the lithotomy position under general anaesthesia (induced with intravenous thiopentone, nitrous oxide, oxygen, trilene, and ether). A full pelvic examination conducted at this time revealed a normal vagina, uterus, and appendages with clear fornices. Examination with a speculum demonstrated that the cervix was healthy. A catheter specimen of urine was sterile on culture and a specimen of pus from the abscess cavity produced a profuse growth of Escherichia coli on culture, which was sensitive to streptomycin, Terramycin, chloramphenicol, and Furadantin.

Result.-The post-operative condition was satisfactory. She was given daily saline baths and twice daily injections of Crystamycin (streptomycin $0.5 \mathrm{~g}$. and penicillin 500,000 units). The temperature fell to $97 \cdot 4^{\circ} \mathrm{F}$. on the first day and she remained afebrile until she was discharged on the fifth day with the wound well healed.

Six weeks later she was examined in the out-patient department and the operation site was found to have

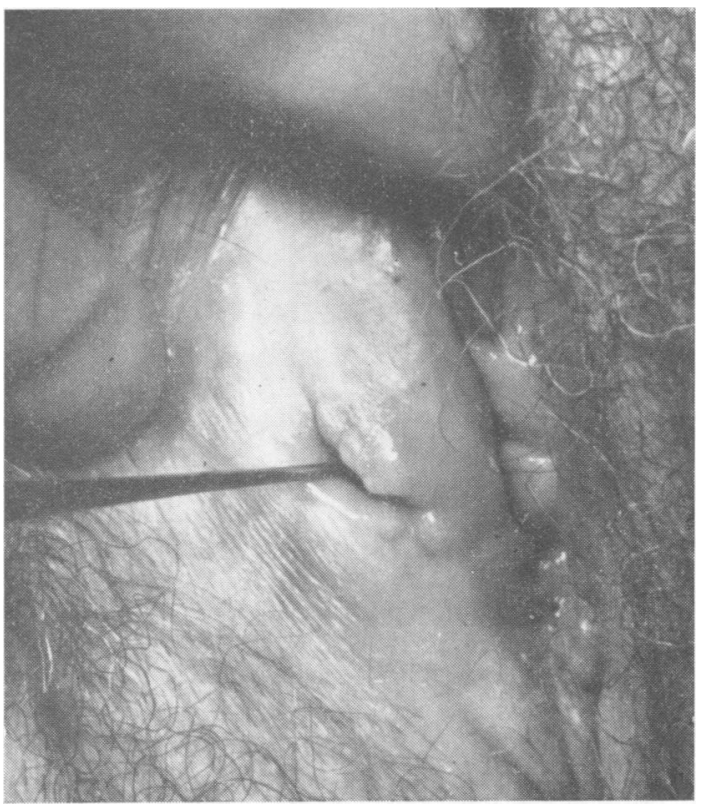

FIG. 3.-Persistent drainage hole with probe in situ 1 month later.

remained healed. A small hole for drainage was visible.

She has since emigrated to New Zealand, but correspondence in March, 1964, indicated that there had been no recurrence of abscess or cyst formation.

Case 2, a 42-year-old woman, was seen in the Venereal Diseases Department of St. Mary's Hospital on October 4, 1963, with a painful swelling on the right side of the vulva. This had been present for a week and had developed one day after extramarital intercourse. (She had been separated from her husband for over a year.) There were no other symptoms. Before her attendance she had been treated with penicillin tablets by her general practitioner without effect. A right-sided Bartholin's abscess had been incised in 1954. She gave no history of venereal infection. The periods were regular and the last one started on September 10,1963. She had two children, one boy and one girl, and had also had two miscarriages at 3 months.

Examination.-On the vulva there was a large tender red swelling $5 \mathrm{~cm}$. in diameter arising in the left labium majus, beneath the line of origin of the labium minus.

Treatment.-She was placed in lithotomy position, the mucosal surface of the abscess was infiltrated with 2 to $3 \mathrm{ml}$. 1 per cent. lignocaine hydrochloride, and marsupialization performed (Fig. 2). A specimen of pus taken from the abscess cavity was sterile on culture. A speculum examination of the vagina and cervix showed no abnormality. Urethral and cervical smears and cultures taken at the same time failed to demonstrate $N$. gonorrhoeae 
and a saline suspension of a loop specimen from the posterior fornix failed to demonstrate Trichomonas vaginalis. A full pelvic examination showed no abnormality, and the Wassermann reaction and gonococcal complement-fixation test were both negative.

Progress.-She was given $1 \cdot 2$ mega units procaine penicillin (PAM) prophylactically and was then inspected daily for the next 5 days for signs of healing. Routine tests for gonorrhoea and $T$. vaginalis performed weekly for two weeks after the operation remained negative. On the 19th day, pus accumulated in the abscess cavity but it was successfully removed and kept dry by irrigating daily with Eusol for the next 5 days. Further routine tests for gonorrhoea and $T$. vaginalis performed weekly for the next 3 weeks and a Wassermann reaction performed 3 months after the first attendance were also negative.

Result.-The patient has since remained quite well; at the time of her last attendance on March 20, 1964, there had been no recurrence and a small hole for drainage persisted at the operation site (Fig. 3).

Case 3, a 22-year-old woman, was seen in the Venereal Diseases Department of St. Mary's Hospital on October 28,1963 , complaining of a lump on the left side of the vulva, which had been present for the past 2 years and had followed an infection. It had become bigger and painful over the preceding 3 days and had been associated with an offensive vaginal discharge, which had developed 5 days previously and 2 days after intercourse with a stranger. There were no other symptoms or history of previous venereal infection. The periods had been regular until September 10,1963, but when seen she was 3 weeks overdue. She had had no previous pregnancies.

Examination.-A Bartholin's abscess $4 \mathrm{~cm}$. in diameter was found on the left side of the vulva. It was thought to have arisen as a result of secondary infection in a previous cyst which had followed an attack of bartholinitis.

Treatment.-She was placed in lithotomy position and the mucosal surface of the abscess was infiltrated with 2 to $3 \mathrm{ml}$. 1 per cent. lignocaine hydrochloride and then marsupialized. A specimen of pus from the abscess cavity was sterile on culture. Examination with a speculum revealed a purulent vaginal discharge in association with cervicitis. Urethral and cervical smears and cultures, however, failed to demonstrate the gonococcus although a considerable number of pus cells were seen on microscopy. A saline suspension of a loop specimen from the posterior fornix failed to demonstrate $T$. vaginalis. The Wassermann reaction and gonococcal complementfixation test were negative. A full pelvic examination, however, revealed that the uterus was enlarged to the size of a 6 weeks' pregnancy and that Hegar's sign was positive.

She was seen daily and on the 3 rd day routine tests for gonorrhoea and $T$. vaginalis were performed and a smear and culture from the cervix demonstrated the presence of gonococcal infection. An injection of $1 \cdot 2$ mega units procaine penicillin was given and she was seen at weekly intervals for the next 3 weeks for routine tests for $N$. gonorrhoeae and $T$. vaginalis, which were negative. During this time, the abscess cavity was found to be healing well but a small hole for drainage persisted.

Progress.-On November 11, a Hogben test was found to be positive, but a self-induced abortion was procured on December 19, and a week later she was admitted to the gynaecological department for evacuation of the uterus under a general anaesthetic. She was given daily injections of penicillin and a course of sulphonamides for 5 days and discharged home. A month later she was seen in the out-patients' department, and it was noted that the uterus had fully involuted and that the abscess cavity had remained healed with the area of drainage remaining patent. The blood Wassermann reaction was again negative.

Result.-She attended again 3 months later, during which time she had remained well and further inspection showed the wound to be healed with adequate drainage.

\section{Discussion}

Three cases of recurrent Bartholin's abscesses are described which illustrate the fact that the operation of marsupialization can be performed under local infiltration analgesia as an out-patient procedure, with results equal to those performed under general anaesthesia as an in-patient. Two cases performed under local infiltration analgesia were found to be well after 6 months and one case performed under general anaesthesia was reported to be well after $3 \frac{1}{2}$ years.

Marsupialization can therefore be successfully performed under local infiltration analgesia in the venereal diseases or other out-patient department. General anaesthesia or the more complicated pudendal nerve block need only be used in the case of a very nervous patient. Complications and recurrences are rare, but if necessary the operation can be repeated. It is of particular value in acute abscesses, since drainage and a curative operation are effected at the same time.

Treatment by simple incision will cause the lining to collapse and granulate, resulting in persistent blockage of the duct, with increased liability to recurrence. Total excision of the gland for recurrent cases is also undesirable, since this results in dryness of the vulva and dyspareunia through loss of secretion; also, in the event of incomplete removal, the abscess recurs. Haematoma formation and painful scarring may also occur as complications.

\section{Summary}

The successful treatment of three cases of recurrent Bartholin's abscesses by marsupialization is described. 
In two cases, one in association with a gonococcal infection, marsupialization was simply performed in the venereal diseases out-patients' department. The results were equal to those obtained by operating on an in-patient under general anaesthesia.

Two cases treated under local infiltration analgesia were each followed up for 6 months and the one case treated under general anaesthesia was followed up for $3 \frac{1}{2}$ years. There has been no recurrence.

I am indebted to $\mathrm{Mr}$ Ambrose King, consultant venereologist, The London Hospital, for criticism and advice in the final preparation of the script; to Mr P. Cowell Barkla, consultant obstetrician and gynaecologist, the Nottingham Hospital for Women, for permission to publish Case 1; to Dr R.R. Willcox, consultant venereologist, St. Mary's Hospital, London, for permission to publish Cases 2 and 3; and to the photographic department, St. Mary's Hospital, for the illustrations.

\section{REFERENCES}

Blakey, D. H. (1958). J. Obstet. Gynaec. Brit. Emp., 65, 800. Davies, J. W. (1948). Surg. Gynec. Obstet., 86, 329.
Jacobson, P. (1950). West. J. Surg., 58, 704. (1960). Amer. J. Obstet. Gynec., 79, 73.

Johnson, W. D. (1961). Obstet. and Gynec., 18, 277.

Novak, E., and Novak, E. R. (1958). "Gynecologic and Obstetric Pathology", 4th ed., p. 18. Saunders, Philadelphia.

Siganos, E. Ch. (1961). Brit. med. J., 2, 995.

Tancer, M. L., Rosenberg, M., and Fernandez, D. (1956). Obstet. and Gynec., 7, 608.

Wilder, E. M. (1955). Sth. med. J. (Bgham, Ala.), 48, 460.

Une méthode de marsupialisation pour abcès récurrents des glandes de Bartholin, faisable en consultation externe RÉSUMÉ

On décrit le traitement par marsupialisation de trois cas d'abcès récurrents des glandes de Bartholin.

Dans deux cas dont l'un associe avec une infection à gonocoques, on fit la marsupialisation dans la consultation externe du service des maladies vénériennes. Les résultats furent aussi bons que ceux obtenus en opérant sous anesthésie générale après admission du malade à l'hôpital.

Les deux cas traités sous anesthésie locale furent suivis pendant 6 mois et le cas traité sous anesthésie générale fut suivi $3 \frac{1}{2}$ ans. Il n'y eut pas de rechutes. 